\title{
Effect of Applied DC Voltage on the Wettability of Zirconia by Liquid Iron and Strengthening of Sprayed Zirconia to Iron
}

\author{
Kiyoshi NOGI, Hiroyuki TAKEDA') and Kazumi OGINO
}

Department of Material Science and Processing, Faculty of Engineering, Osaka University, Yamadaoka, Suita, Osaka-fu, 565 Japan.

1) Graduate Student, Osaka University.

(Received on February 13, 1990; accepted in the final form on May 18, 1990)

Field assisted bonding of metal to zirconia utilizing the oxygen ionic conductivity of zirconia has been examined. A strengthening of sprayed zirconia to iron was attempted after spraying zirconia onto the iron substrate. And the effect of applying a DC voltage to the interface on the wettability of zirconia by liquid iron was also investigated because the liquid phase would be formed at the interface by applying a DC voltage to the sprayed zirconia-metal system. According to applying a DC voltage, the interfacial chemical reaction occurs at the interface. The joining strength can be improved even after spraying zirconia onto the metal substrate. And the wettability of zirconia by liquid iron was also improved. Results are summarized as follows:

(1) Application of a DC voltage to the interface can bring about the oxidation of iron and the deoxidation of zirconia to metallic zirconium at the interface.

(2) Two mechanisms can be considered for joining of zirconia to iron. They are the penetration of iron-oxide formed at the interface into the grain boundary of zirconia and the reaction between iron and metallic zirconium at the interface.

(3) This joining method is the new one to strengthen the sprayed zirconia after spraying it.

(4) This joining method has the advantage of not needing pretreatment of the substrate (e.g., sand blast or spraying metallic bond coat between substrate and zirconia overlayer, etc.).

KEY WORDS: zirconia; iron; ceramics; spraying; joining; wettability.

\section{Introduction}

The recent development of industrial technology demands superior materials to superalloys. ${ }^{11}$ Ceramics are expected to be important materials for industrial applications because they have excellent properties, such as heat-, wear- and corrosion-resistance.

Thermal barrier coatings, especially spraying of oxides, are expected to be one of the most important candidates to get rid of shortcomings of metals. Zirconia ceramics are widely used as spraying ccramics materials due to its low thermal conductivity, high melting point and high thermal expansion coefficient.2) However, the joining strength between metal substratcs and sprayed ceramics are generally weak and the metallic bond coat was often presprayed onto the metal substrate to improve it. ${ }^{2,3)}$ Kuribayashi et al.4) have reported the method to improve the joining strength after spraying zirconia. In their method, the improvement of the joining strength was not attained by a chemical reaction between coated layer and substrate but by a complete densification of coated layer.

The authors ${ }^{5,6)}$ have already reported the method to join the sintered zirconia to copper and iron. In our method, the chemical reaction occurs at the interface by applying a DC voltage using the oxygen ionic conductivity of zirconia at elevated temperature and the reaction contributes to the joining of zirconia to metals. The mechanical anchoring effect is now considered to be the main joining mechanism between metal substrate and sprayed ceramics.7) As a metal substrate-sprayed zirconia system is expected to have the identical interface with a metal-sintered zirconia system, the method is also expected to be effective to improve the joining strength between metal substrate and sprayed zirconia, although it has never been reported.

The improvement of the joining strength between iron and sprayed zirconia was attempted by applying a DG voltage to the iron-zirconia interface, after spraying zirconia onto the iron substrate. Furthermore, the improvement of the wettability of zirconia by liquid iron was also attempted by applying a DC voltage because the wettability is an important factor in the joinings.

\section{Experiment}

\subsection{Iron-Zirconia Joining}

\subsubsection{Samples}

Iron was used as the metal substrate. It was made from electrolytic iron by vacuum-melting. The ironzirconia specimen was made by plasma-spraying of $\mathrm{Y}_{2} \mathrm{O}_{3}$ stabilized zirconia onto the iron substrate which had a $10 \mathrm{~mm} \times 10 \mathrm{~mm}$ square face. Although the general thickness of sprayed ceramics is only $0.2-0.3$ $\mathrm{mm}$, which is considered to be enough for thermal 
barrier coatings, ${ }^{1)}$ that of sprayed zirconia in the present study was about $2 \mathrm{~mm}$ to clarify the effect of applying a DG voltage and to observe interfacial phenomena easily. The surface of the iron substrate was optically flat by polishing on emery papers. Sandblast treatment was not carried out in order to clarify the effect of a DG voltage.

\subsubsection{Voltage Treatment}

Joining treatments were carried out in Ar atmosphere with the assembly shown in Fig. 1. The treatments were carried out at 1243,1573 and $1673 \mathrm{~K}$. After the specimen had been heated up to a scheduled temperature, a DC voltage was applied to the ironsprayed zirconia interface under various applying conditions. After finishing applying a DC voltage, the sample was cooled down to room temperature at an average cooling rate of $4-5 \mathrm{~K} / \mathrm{min}$. After the treatment, the interface between the sprayed zirconia and iron was examined by EPMA.

Joining strength between the iron substrate and the sprayed zirconia was evaluated by dropping a steel ball $(5.48 \mathrm{~g}, 11 \mathrm{~mm}$ in diameter) onto the sprayed zirconia. When the joining strength could not be evaluated clearly, a thermal cycle test $[R . T . \rightarrow 1173 \mathrm{~K}$ $\rightarrow R$.T.] was conducted. Experimental temperatures, the eutectic points of $\mathrm{FcO}-\mathrm{ZrO} \mathrm{rO}_{2}$ and $\mathrm{Fe}-\mathrm{Zr}$ systems and the melting point of $\mathrm{FeO}$ are listed in Table 1 .

\subsection{Wettability Evaluation of Zirconia by Liquid Iron}

As can be seen from Table 1, it can be predicted that a liquid phase would be formed at the ironzirconia interface when an iron is oxidized to $\mathrm{FeO}$ or the zirconia is deoxidized to metallic zirconium at the interface in the present expcrimental temperatures. Application of a DC voltage results in the migration

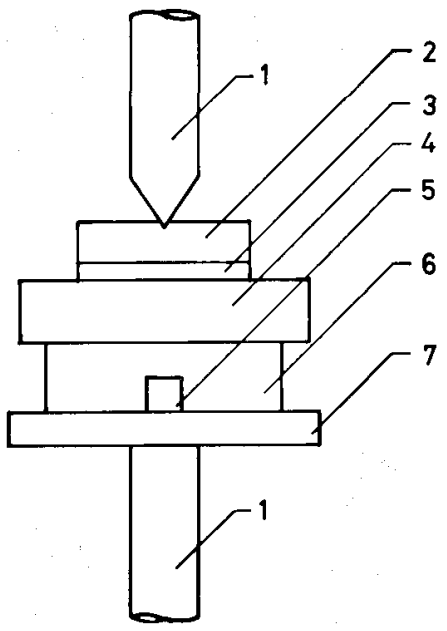

1: Stainless rod

2: Iron sample

3: Sprayed zirconia sample

4: Zirconia disk

5: Hole

6: Zirconia pipe

7: Iron disk

Fig. 1. Schematic representation of $\mathrm{Fe}$-sprayed $\mathrm{ZrO}_{2}$ joining assembly.

Table 1. Eutectic points of $\mathrm{Fe}-\mathrm{Zr}$ and $\mathrm{FeO}-\mathrm{ZrO}_{2}$ systems and melting point of $\mathrm{FeO}$.

$\begin{array}{ll}\text { Eutectic point of } \mathrm{FeO}-\mathrm{ZrO}_{2} \text { system } & 1603 \mathrm{~K} \\ \text { Melting point of } \mathrm{FeO} & 1650 \mathrm{~K} \\ \text { Eutectic point of } \mathrm{Fe}-\mathrm{Zr} \text { system } & 1207 \mathrm{~K}\end{array}$

of oxygen ions in stabilized zirconia. Many work$\operatorname{ers}^{8-15)}$ have investigated the effect of oxygen on the wettability of solid oxides by liquid metals and concluded that oxygen strongly affects it. Therefore the effect of application of a DC voltage on the wettability of zirconia by liquid iron was studied using the sessile drop method. Zirconia sample employed was 11 mol\% $\%$ CaO-stabilized sintered zirconia. Experimental procedure and apparatus were previously reported. ${ }^{16)}$ The wettability was evaluated by measuring a change in the contact angle or interface area before and after applying a DC voltage. The experiment was carried out at $1853 \mathrm{~K}$.

\section{Results and Discussion}

\subsection{Wetting Experiment}

The effect of application of a DC voltage on the wettability of zirconia by liquid iron was studied when a DG voltage was applied to supply oxygen ions to liquid iron-zirconia interface. Then the zirconia was attached to the cathode. The typical result is shown in Fig. 2. Contact angle between liquid iron and zirconia substrate decreased when a DC voltage was applied to the interface. An increase of the interfacial area was about $17 \%$. The result was the same as that observed in the liquid copper-zirconia system. ${ }^{16)}$

Fig. 3 shows the schematic of a liquid droplet on a solid substrate at equilibrium state. The relationship among three kinds of free energies is defined by Young's cquation (1) using contact angle, $\theta$,

$$
\gamma_{\mathrm{S}}=\gamma_{\mathrm{L}} \cdot \cos \theta+\gamma_{\mathrm{LS}}
$$

where, $\gamma_{\mathrm{s}}:$ surface free energy of the zirconia $\gamma_{\mathrm{L}}:$ surface frec energy of the liquid iron

$\gamma_{\mathrm{LS}}$ : interfacial free energy between liquid iron and zirconia.

A decrease in surface free energy of the liquid iron,

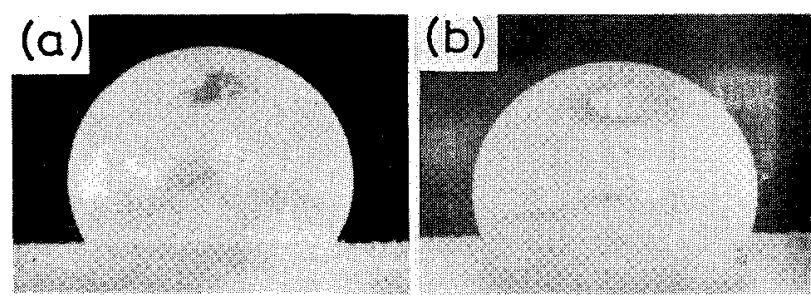

(a) Before applying a $\mathrm{DC}$ voltage

(b) After applying a DC voltage

Fig. 2. Change in shape of Fe droplet on $\mathrm{ZrO}_{2}$ with applying a DG voltage at $1853 \mathrm{~K}$.

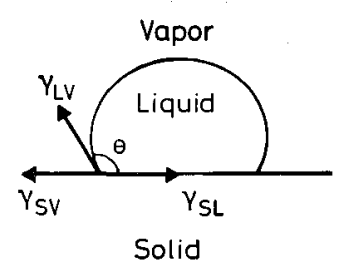

Fig. 3. Schematic of liquid droplet on solid substrate. 
$\gamma_{L}$, and interfacial free energy between liquid iron and zirconia, $\gamma_{L S}$, results in a decrease in the contact angle. As will be explained later, $\mathrm{FeO}$ would be formed at the interface by the reaction between iron and oxygen which was supplied by applying a DC voltage. A reaction between $\mathrm{FeO}$ and zirconia at the interface and an incrcase in the amount of oxygen, which is a surface-active element, can be expected. When a DG voltage was applied to supply oxygen ions to the interface, a decrease in $\gamma_{L S}$ and $\gamma_{L}$ can be expected.

When a DG voltage was not applied, no reaction was observed at the interface. This suggests that interfacial free energy between liquid iron and zirconia did not change. The surface tension of liquid droplet can be measured correctly by the sessile drop method, when mass of a liquid metal is about $2 \mathrm{~g} .{ }^{17}$ ) In this work the mass of liquid iron employed was about $0.5 \mathrm{~g}$. It was judged that it was difficult to measure the surface tension correctly.

The contact angle did not change with time. As it was reasonable to assume that surface free energy of the zirconia was constant, the surface free energy of the liquid iron did not change. An amount of free oxygen on the liquid surface, which determines the surface free energy of liquid surface, would depend on oxygen partial pressure in atmosphere. So it can be considered that oxygen partial pressure would not change during the experiment. The surface free energy is expected to be constant even if a $\mathrm{DC}$ voltage is applied. Accordingly, it can be expected that the decrease in contact angle was attributed only to the decrease in the interfacial free energy due to the reaction between $\mathrm{FeO}$ and zirconia at the interface.

Fig. 4 shows SEM and Fe $\mathrm{K} \alpha$ image in the vicinity of the interface. It can be observed from Fig. 4 that iron penetrated into the grain boundary of zirconia by applying a DC voltage and the reaction occurred at the interface. But Fig. 2 shows that the liquid iron did not wet the zirconia after applying a $\mathrm{DC}$ voltage. When the wettability experiment was car- ried out, the vibration of the drop, which was caused by an evolution of gas bubbles, was observed. Since the gas bubbles made the drop jump and move around on $\mathrm{ZrO}_{2}$ substrate, it can be considered that an enough supply of oxygen which was required for the interfacial reaction between liquid iron and $\mathrm{ZrO}_{2}$, which decreased the interfacial free energy, could be cut off. It is considered that movement of the liquid droplet due to the vibration and no change in the surface free energy of the liquid droplet would result in this non-wetting state.

When a DC voltage was applied, the degree of decrease in contact angle in the present experiment was smaller than that observed in liquid copperzirconia system. ${ }^{16)}$ This difference can be explained as follows:

One of the authors $\left.{ }^{9}\right)$ have reported that either of following reactions occurs at the interfaces when liquid metal-oxygen alloy reacts with oxide. And it was concluded that the reaction occurs between oxide and the lower oxide of the liquid metal.

$$
\begin{aligned}
& \mathrm{Me}+x \cdot \underline{\mathrm{O}} \text { (in } \mathrm{Me})+y \cdot \mathrm{MO}=\mathrm{MeO}_{x} \cdot y \mathrm{MO} \\
& \text { or } \left.\mathrm{Me}+x \cdot \underline{\mathrm{O}} \text { (in } \mathrm{Me})=\underline{\mathrm{MeO}}_{x} \text { (in } \mathrm{MO}\right)
\end{aligned}
$$

where, Me: Metal

MO: Oxide

$\mathrm{MeO}_{x} \cdot y \mathrm{MO}:$ a compound between oxide and the lower oxide of the liquid metal

$\underline{\mathrm{MeO}_{x}}$ (in MO): a continuous series of solid solution.

When a DC voltage was applied to supply oxygen ions to the interface, high oxygen potential was retained at the interface. $\mathrm{FeO}$ is expected to form in liquid iron-zirconia system and $\mathrm{Cu}_{2} \mathrm{O}$ in liquid copper-zirconia system from above information. The melting points of $\mathrm{FeO}$ and $\mathrm{Cu}_{2} \mathrm{O}$ are respectively 1650 and $1503 \mathrm{~K}$. And the experimental temperatures were 1853 and $1423 \mathrm{~K}$, respectively, in liquid iron-zirconia and in liquid copper-zirconia system. It is obvious that this experimental temperature was
的

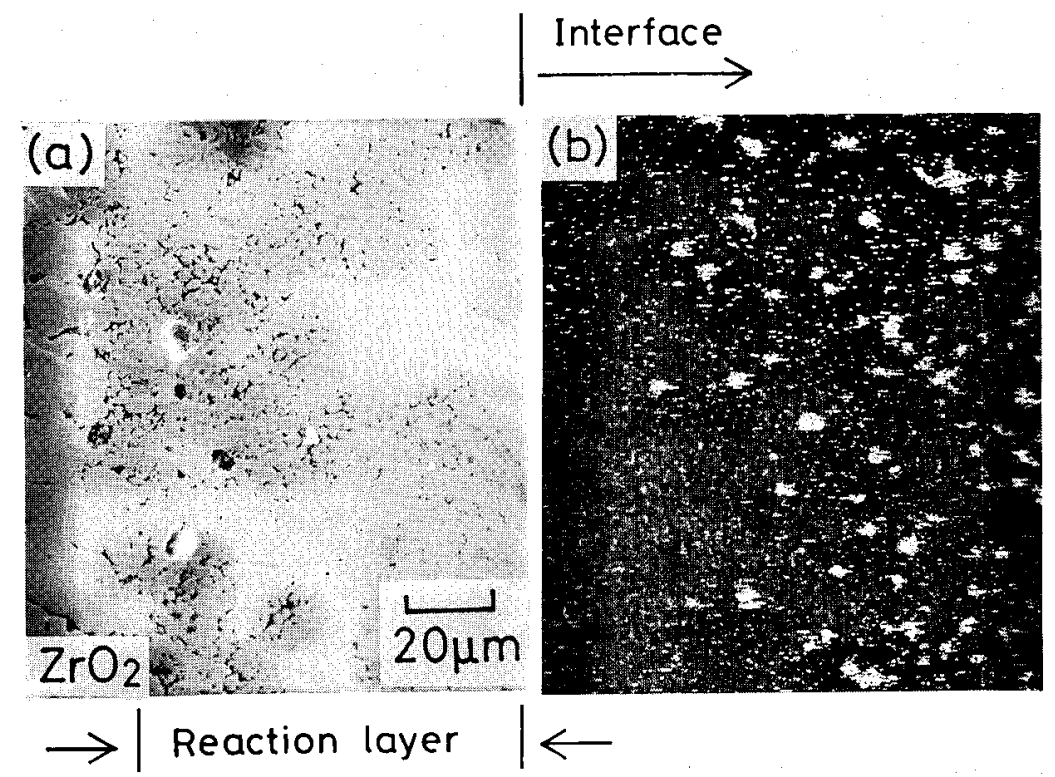

(a) SEM (b) Fe K $\alpha$ image

Fig. 4.

SEM and $\mathrm{X}$-ray image at the $\mathrm{Fe}-\mathrm{ZrO}_{2}$ interface treated at $1853 \mathrm{~K}$. 
higher than the melting point of $\mathrm{FeO}$. It is considered that liquid $\mathrm{FeO}$ rapidly dissolves into the liquid droplet even if $\mathrm{FeO}$ is formed at the interface. In the liquid copper-zirconia system, solid $\mathrm{Cu}_{2} \mathrm{O}$ is expected to be more difficult to dissolve into liquid copper droplet. This difference results in the difference in the interfacial reactions. A reaction enough to decrease the interfacial free energy cannot be expected to occur at the interface in liquid iron-zirconia system. This may be the reason why a large decrease in contact angle was not observed in the present work.

Fig. 5(a) shows the principle when a stabilized zirconia operates as an oxygen sensor. An electromotive force, $E$, corresponding to the difference in oxygen potential can be yielded at the ends of zirconia. Wagner ${ }^{18)}$ derived the equation for calculating the electromotive force. When ambient temperature and oxygen potential belong to the electolytic domain, it is possible to calculate the value of $E$ using Eq. (2).

$$
E=(R \cdot T / 4 / F) \cdot \ln \left\{P_{\mathrm{O}_{2}}(\mathrm{I}) / P_{\mathrm{O}_{2}}(\mathrm{II})\right\}
$$

where, $\quad F$ : Faraday constant

$$
\begin{aligned}
P_{\mathrm{O}_{2}}(\mathrm{I}): & \text { oxygen potential }(\mathrm{I}) \\
P_{\mathrm{O}_{2}}(\mathrm{II}): & \text { oxygen potential (II) } \\
R: & \text { gas constant }
\end{aligned}
$$$$
T \text { : absolute temperature. }
$$

Fig. 5(b) shows the experimental principle of this work. A DG voltage was applied to a metal-zirconia interface by an external DC power supply in series with the assembly. It can be seen that zirconia operates as an "oxygen pump". It produces the difference in oxygen potentials at the ends of the zirconia corresponding to applied voltage, $E_{0}$, across the metal-zirconia specimen. It is impossible to evaluate the correct value of oxygen potential at the metal-zirconia interface according to following reasons;

(1) Oxygen potential at the reference electrode cannot be determined.

(2) Various resistances, such as contact resistance and resistance of materials employed, cannot be estimated in the electrical circuit.

It can be expected that higher oxygen potential is retained at the metal-zirconia interface when a DC voltage is applied to supply oxygen ions to the interface. This is supported by the fact that iron was oxidized at the interface by applying a $1 \mathrm{C}$ voltage.

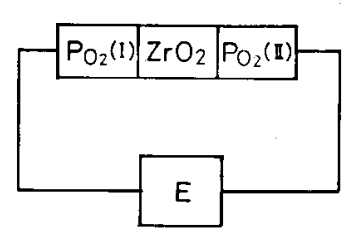

(a)

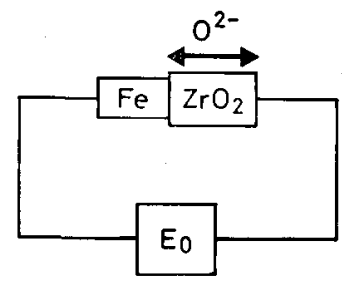

(b) (a) The principle of zirconia oxygen sensor

(b) The principle of this work

Fig. 5. Explanatory figures.
It is apparent that oxygen potential at the metalzirconia interface can be controlled by an external DC power supply.

Fig. 6 shows a typical result observed in the wettability experiment when a DC voltage was applied to remove oxygen ions from a liquid iron-zirconia interface. The zirconia was attached to cathode. The shape of liquid iron droplet was deformed and interfacial area was increased a little (about $1 \%$ ) by applying a DC voltage. It is expected that wettability of zirconia by liquid iron was improved. This figure also shows that new phase was formed on the liquid surface since metallic luster disappeared by the application. EPMA analysis clarified that this phase was a zirconia. These results were the same as those obscrved in the liquid copper-zirconia system. ${ }^{16)}$ Application of a DC voltage resulted in a reduction of zirconia to metallic zirconium at the interface. After that, the zirconium dissolved into the liquid iron droplet, and the zirconium was oxidized by oxygen in atmosphere on the surface of the iron droplet.

Fig. 7 shows SEM and $\mathrm{Zr}$ line analysis across the interface. It can be seen from the figure that a reaction layer was formed at the interface by applying a DC voltage. Zirconia was considered to be deoxidized at the $\mathrm{Fe}-\mathrm{ZrO}_{2}$ interface. This phenomenon can be also explained qualitatively from a

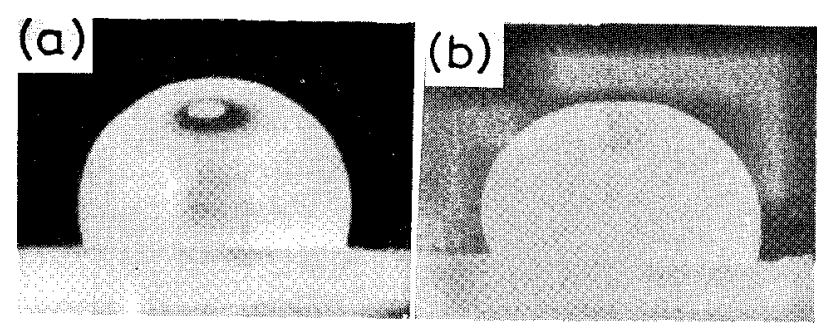

(a) Before applying a DG voltage

(b) After applying a $\mathrm{DG}$ voltage

Fig. 6. Change in shape of $\mathrm{Fe}$ droplet on $\mathrm{ZrO}_{2}$ with applying a $\mathrm{DC}$ voltage at $1853 \mathrm{~K}$.

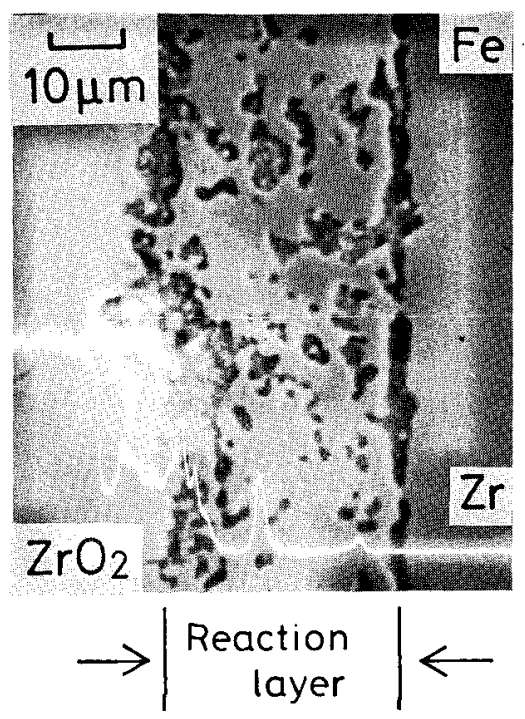

Fig. 7. SEM and $\mathrm{Zr}$ line analysis at the $\mathrm{Fe}-\mathrm{ZrO}_{2}$ interface treated at $1853 \mathrm{~K}$. 
viewpoint that the zirconia operates as an "oxygen pump". Application of a DG voltage to remove oxygen ions from the interface would result in a decrease in oxygen potential at the interface. Under this condition, it is possible to deoxidize $\mathrm{ZrO}_{2}$ at the interface. It is considered that a shape changing process would resemble to that in the liquid copperzirconia system. ${ }^{16)}$ However, the degree of a decrease in contact angle was smaller than that in the liquid copper-zirconia system. This may be attributed to the fact that the new phase on the liquid droplet prevented the liquid iron from spreading and that enough interfacial reaction could not occur because of a decrease in ionic transference number at elevated temperatures. It gets clear that application of a DC voltage improves the wettability of zirconia by liquid iron. An interfacial reaction can be brought about by applying a DG voltage even if an ionic transference number is not unit and the amount of oxygen to be moved is decreascd. And it can be expected that this number strongly affects the wettability.

\subsection{Spraying Experiment}

Joining experiments were carried out when a DG voltage was applied to supply oxygen ions to the interface. Table 2 shows applying conditions and joining strength.

Fig. 8 shows SEM and Fe $\mathrm{K} \alpha$ image in the vicinity of the interface. High joining strength was obtained by applying a DC voltage. Iron penetrated into the grain boundary of zirconia by applying a $D C$ voltage. And iron and zirconia were mechanically anchored with each other. This penetration of iron and the

Table 2. Experimental conditions and results of joining of sprayed zirconia to iron.

\begin{tabular}{cccc}
\hline \multicolumn{3}{c}{ Experimental conditions } & Results \\
\cline { 1 - 2 } $\begin{array}{c}\text { Temp. } \\
(\mathrm{K})\end{array}$ & $\begin{array}{c}\text { Quantity } \\
(\mathrm{C})\end{array}$ & $\begin{array}{c}\text { Time } \\
(\mathrm{s})\end{array}$ & $\begin{array}{c}\text { Joinirg } \\
\text { strength* }\end{array}$ \\
\hline 1673 & 15 & 75 & N. J. \\
1673 & 100 & 500 & $>400$ \\
1673 & 1000 & 5000 & N. J. \\
\hline
\end{tabular}

*: Number of cycles

N. J. : Not joining reaction between $\mathrm{FeO}$ and $\mathrm{ZrO}_{2}$ are expected to be the joining mechanisms. As reported in the previous work, ${ }^{6)}$ iron was oxidized to $\mathrm{FeO}$ at the interface when a DC voltage was applied to supply oxygen ions to the interface. As the experimental temperature, $1673 \mathrm{~K}$, was higher than the melting point of $\mathrm{FeO}$, $1650 \mathrm{~K}$, it could be considered that liquid $\mathrm{FeO}$ penetrated into the grain boundary. As shown in Fig. 1, the joining was accomplished without any load except for a weigh of upper stainless rod. Under these conditions, it might be favorable for iron-zirconia joining that liquid phase wetted the zirconia.

When the joining experiment is carried out, following conditions are retained.

(1) It is possible to apply a DG voltage continuously even if liquid phase is formed at the interface.

(2) Higher oxygen potential is retained at the interface by applying a DG voltage.

When oxygen was supplied to the interface by applying a $\mathrm{DC}$ voltage, iron was oxidized to $\mathrm{FeO}$. As the experimental temperature was higher than the melting point of $\mathrm{FeO}$, the $\mathrm{FeO}$ was liquid. When zirconia is joined to iron, iron is solid. So this liquid $\mathrm{FeO}$ could be at the iron-zirconia interface. $\mathrm{FeO}$ could react with zirconia easily because the experimental temperature was higher than the eutectic point of $\mathrm{FeO}-$ $\mathrm{ZrO}_{2}$ system. Furthermore, the results obtained in the wettability experiments also indicates that application of a DG voltage could improve the wettability of zirconia by liquid phase. It can be expected that the liquid phase which is formed at the interface by application of a DC voltage would wet the zirconia. Accordingly, iron penetrated into the grain boundary of zirconia and the joining was attained without any load upon the interface.

Some experiments were carried out in order to deoxidize the $\mathrm{FeO}$ by applying a DG voltage to remove oxygen ions from the interface after supplying oxygen ions to the interface since $\mathrm{FeO}$ is considered to be brittle. Table 3 shows applying conditions and joining strength. It was not clear which applying method was better for the joining. However, it is obvious that an effective improvement of the joining strength was attained under proper applying condi-

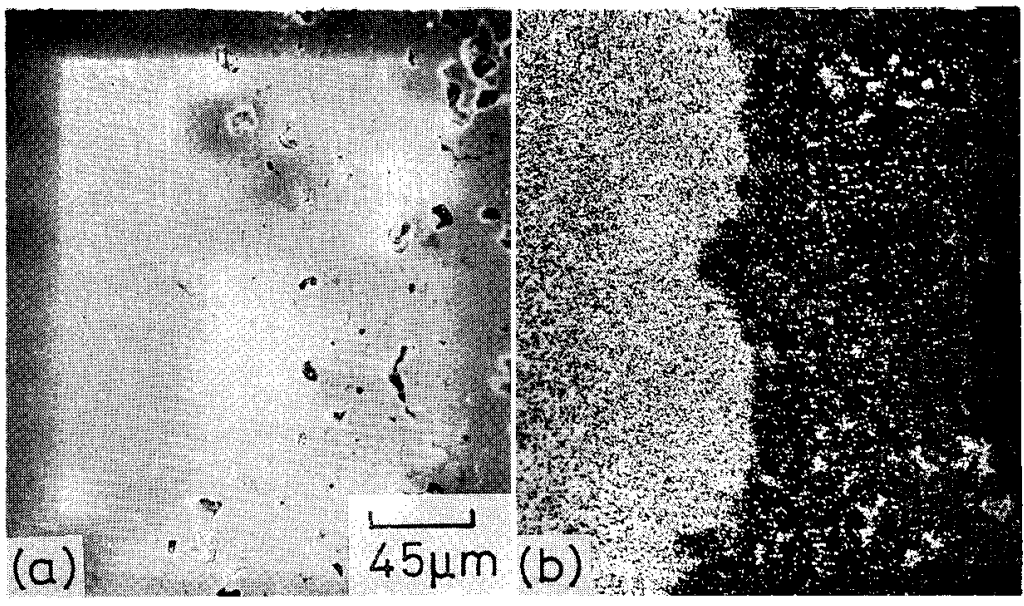

(a) SEM

(b) $\mathrm{Fe} \mathrm{K} \alpha$ image

Fig. 8.

SEM and X-ray image at the $\mathrm{Fe}-\mathrm{ZrO}_{2}$ interface treated at $1673 \mathrm{~K}$. 
tion and at experimental temperature. Fig. 9 shows $\mathrm{SEM}$ and $\mathrm{Fe} \mathrm{K} \alpha$ images in the vicinity of the interfaces. As the same applying condition was employed in these cases, a difference in the temperature should be attributed to a difference in the interfacial aspects. The melting point of $\mathrm{FeO}$ is $1650 \mathrm{~K}$. So it is considered that the temperature becomes to be a very important factor in the control of the penetration of the iron. When the interfacial aspect was examined by EPMA, some pores could be observed across the interface. When joining strength was improved, iron penetrated into the grain boundary about one zirconia particle distance and filled up the pores at the interface. Iron substrate and sprayed zirconia an-

Table 3. Experimental conditions and results of joining of sprayed zirconia to iron.

\begin{tabular}{|c|c|c|c|c|c|c|}
\hline \multicolumn{3}{|c|}{ (I) } & \multicolumn{3}{|c|}{ (II) } & \multirow{2}{*}{$\underset{\text { strength* }}{\text { Joining }}$} \\
\hline $\begin{array}{l}\text { Temp. } \\
(\mathrm{K})\end{array}$ & $\begin{array}{l}\text { Quantity } \\
\text { (C) }\end{array}$ & Time & $\begin{array}{l}\text { Temp. } \\
\text { (K) }\end{array}$ & $\begin{array}{l}\text { Quantity } \\
\text { (C) }\end{array}$ & $\underset{(s)}{\text { Time }}$ & \\
\hline 1673 & 0 & 510 & - & 一 & - & N. J. \\
\hline 1673 & 100 & 500 & 1673 & 500 & 2500 & N.J. \\
\hline 1673 & 100 & 500 & 1573 & 500 & 2500 & $>400$ \\
\hline * & \multicolumn{6}{|c|}{ Number of cycles } \\
\hline N.J. : & \multicolumn{6}{|c|}{ Not joining } \\
\hline (I) & \multicolumn{6}{|c|}{$\begin{array}{l}\text { Application of a DC voltage to supply oxygen ions to } \\
\text { the iron-zirconia interface }\end{array}$} \\
\hline (II) : & \multicolumn{6}{|c|}{ Application of a $\mathrm{DC}$ voltage to remove oxygen ions } \\
\hline
\end{tabular}

chored with each other. As a comparatively long applying time, $2.5 \mathrm{ks}$, was adopted, iron penetrated deeply into the grain boundary of zirconia. The thermal stress was yielded in the vicinity of the interface due to a difference in thermal expansions between iron and zirconia while the specimen was cooled down. Then the more the residual strain increases, the less the resistivity to this stress decreases. Moreover, the deeper iron penetrates, the more the residual stress increases. Accordingly, a control of penctration depth of iron into the grain boundary of zirconia is required in order to improve the joining strength. The temperatures and applying conditions determine the depth. They can be controlled easily by an external DC power supply.

A DC voltage was applied to remove oxygen ions from the interface in some experiments. Table 4 shows applying conditions and joining strength. As can be seen from Table 4, effective improvement of joining strength was also attained.

Fig. 10 shows the microstructure of the interface which gave high joining strength. Application of a $D G$ voltage caused the reaction between iron and zirconium. The existence of $\alpha-\mathrm{Zr}$ and $\mathrm{Fe}_{2} \mathrm{Zr}$ on the zirconia side interface was confirmed by X-ray analysis after the experiments. As oxygen potential at the interface decreases by applying a DC voltage to remove oxygen ions, zirconia is deoxidized to the metallic zirconium, which react with iron at the interface. This reaction improves the joining strength.
Temperature at which oxygen was removed from the interface:

$$
\begin{aligned}
& \text { (a), (b): } 1673 \mathrm{~K} \\
& \text { (c), (d): } 1573 \mathrm{~K}
\end{aligned}
$$
(a) SEM
(b) $\mathrm{Fe} \mathrm{K} \alpha$ image
(c) SEM
(d) $\mathrm{Fe} \mathrm{K} \alpha$ image

Fig. 9.

SEM and $\mathrm{X}$-ray images at the $\mathrm{Fe}-\mathrm{ZrO}_{2}$ in. terface.

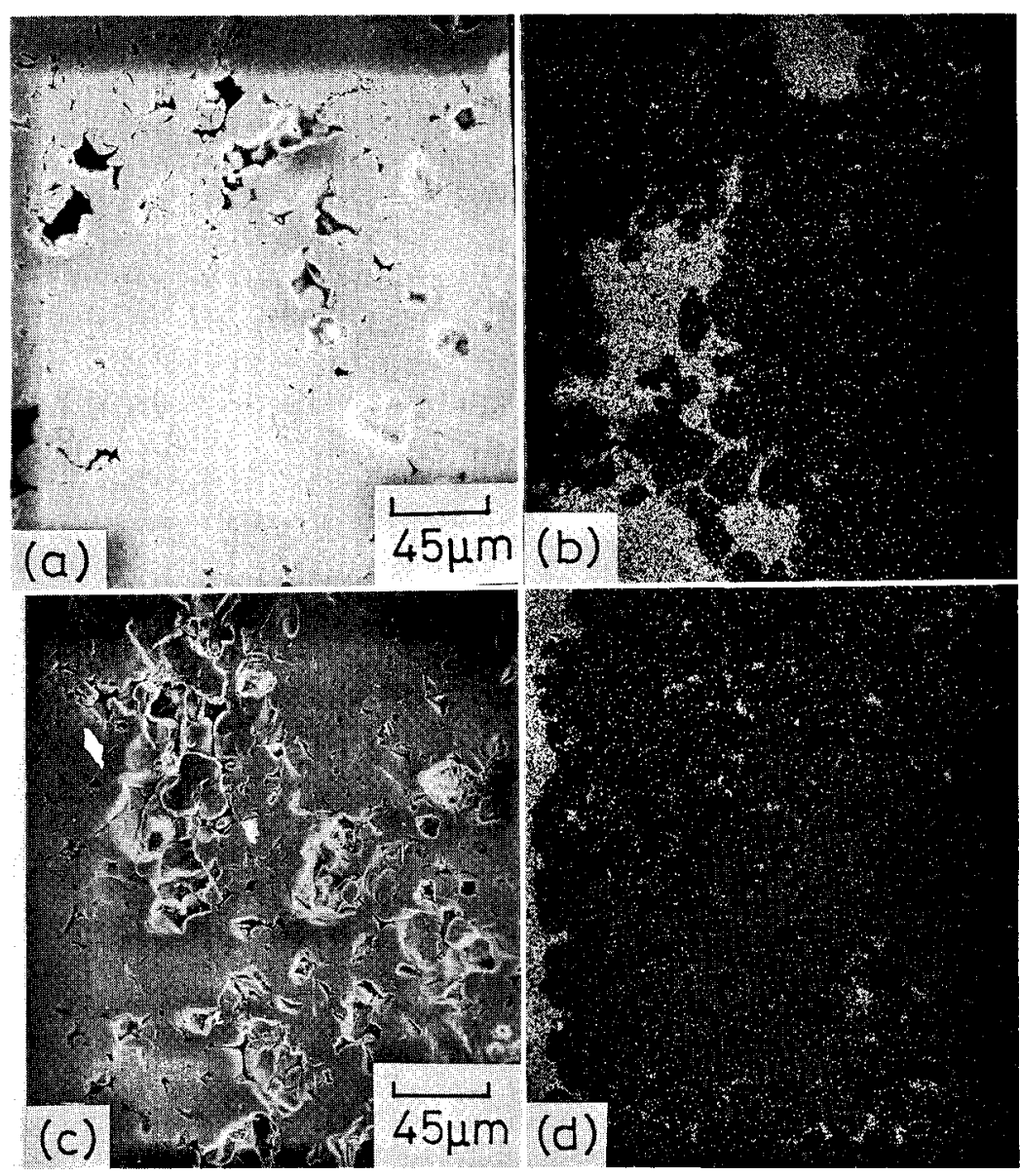


As shown in Table 4, since the experimental temperature was higher than the eutectic point of $\mathrm{Fe}-\mathrm{Zr}$ system, ${ }^{19)}$ the liquid phase would form at the interface. As the liquid phase is expected to wet the zirconia from the results in the wettability experiments, the attainment of the joining without any load upon the interface are supported. When the experiments were carried out at $1243 \mathrm{~K}$, joining strength did not depend on the applied electric quantities. While a DG voltage is applied to remove oxygen ions from the interface, oxygen atoms in atmosphere go into the zirconia from the metal-zirconia-vapor inter-

Table 4. Experimental conditions and results of joining of sprayed zirconia to iron.

\begin{tabular}{cccccc}
\hline \multicolumn{2}{c}{ Experimental conditions } & & \multicolumn{2}{c}{ Results } \\
\cline { 1 - 1 } \cline { 5 - 6 } $\begin{array}{c}\text { Temp. } \\
\text { (K) }\end{array}$ & $\begin{array}{c}\text { Quantity } \\
(\mathrm{C})\end{array}$ & $\begin{array}{c}\text { Time } \\
(\mathrm{s})\end{array}$ & & $\begin{array}{c}\text { Joining } \\
\text { strength* }\end{array}$ & $\begin{array}{c}\text { Heat } \\
\text { Cycle* }\end{array}$ \\
\hline 1243 & 0 & 0 & & $>400$ & 0 \\
1243 & 5 & 250 & & $>400$ & $>5$ \\
1243 & 14.4 & 720 & & $>400$ & N. T. \\
1243 & 144 & 7200 & & $>400$ & N. T. \\
1243 & 403.2 & 20160 & & $>400$ & N. T. \\
1243 & 450 & 22500 & & $>400$ & $>5$ \\
1673 & 60 & 30 & & N. J. & N. T. \\
1673 & 600 & 300 & & N. J. & N. T. \\
\hline
\end{tabular}

* : Number of cycles

N. J. : Not joining

N.T. : Not tested face as reported in the previous work. ${ }^{16)}$ So the amount of oxygen which is generated at the interface by the deoxidation of zirconia is not proportional to the applied clectric quantities. This could be the reason why joining strength did not depend on the applied electric quantities.

Moreover, experimental temperature is a very important factor to improve the joining strength.

Fig. 11 shows SEM and Fe $\mathrm{K} \alpha$ image in the vicinity of the interface at $1673 \mathrm{~K}$. As is clear from Fig. 11, iron penetrated into the grain boundary of zirconia. This was different from the one observed at $1243 \mathrm{~K}$. The higher the temperatures are, the more the resistivity of zirconia and the ionic transference number decrease. When a DG voltage is applied, a voltage across the ends of zirconia becomes smaller when the temperature is higher. As seen from Eq. (2), then, the difference in oxygen potentials also becomes smaller. Oxygen potential at the interface is not low enough to deoxidize zirconia. It is considered that many oxygen would go into the interface from the metalzirconia-vapor interface to supply oxygen ions. And iron was oxidized to FeO.

Recently, much attention has been paid to the joining of ceramics to metals and many joining methods of these materials have been proposed. Some methods are demonstrated by taking notice of the oxygen state at metal-ceramics interfaces. For example, Sakata et al. ${ }^{20)}$ has reported that the joining of $\mathrm{Al}_{2} \mathrm{O}_{3}$ to $\mathrm{Fe}$ can be attained by inserting $\mathrm{FeO}$ into
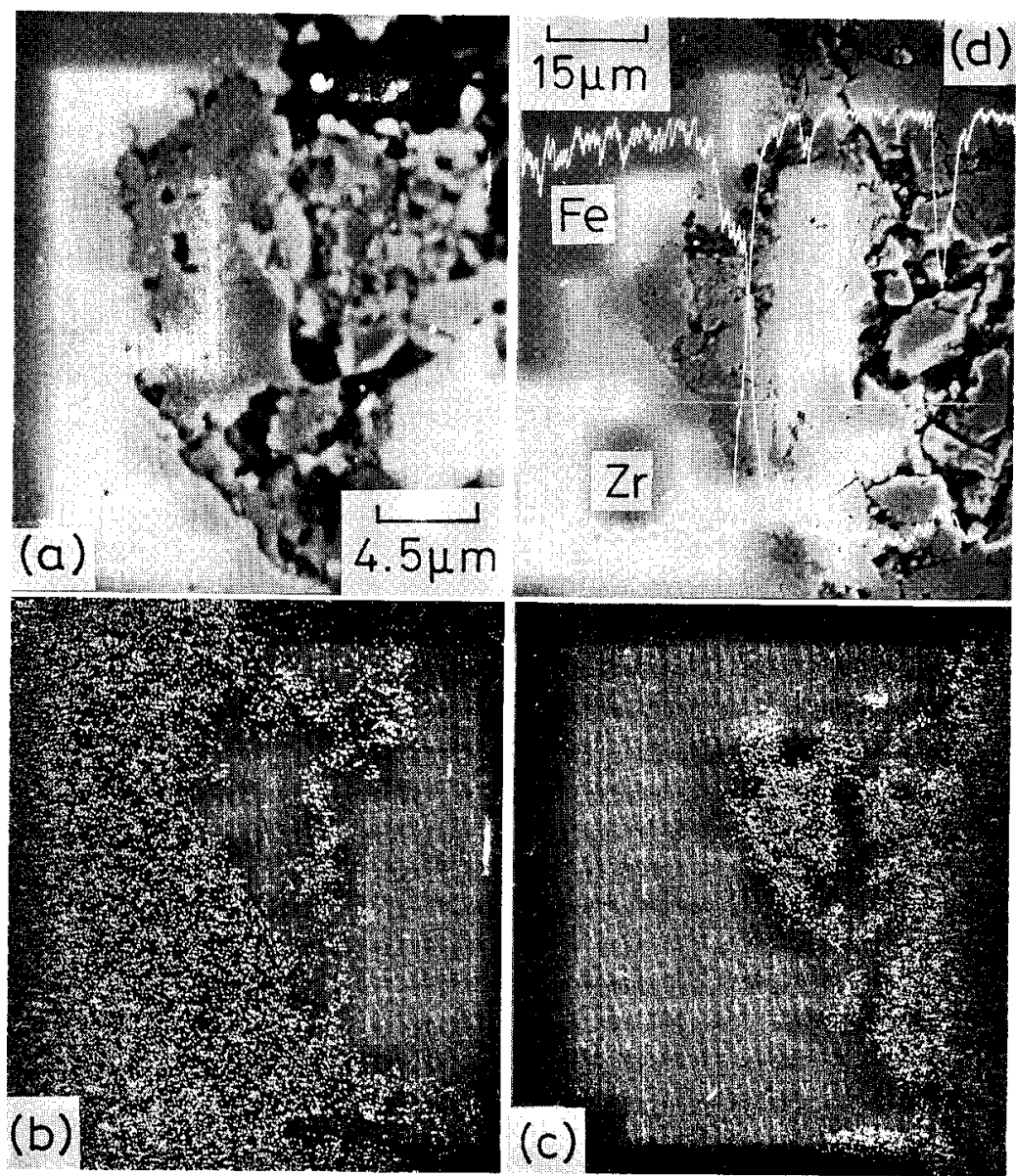

(a) SEM

(b) Fe Kar image

(c) $\mathrm{Zr} \mathrm{K} x$ image

(d) $\mathrm{Fe}$ and $\mathrm{Zr}$ line analyses

Fig. 10.

$\mathrm{SEM}, \mathrm{X}$-ray images and $\mathrm{Fe}$ and $\mathrm{Zr}$ line analyses at the $\mathrm{F} c-\mathrm{ZrO}_{2}$ interface trcated at $1243 \mathrm{~K}$. 
(a) SEM

(b) Fe $\mathrm{K} \alpha$ image

Fig. 11 .

SEM and $\mathrm{X}$-ray image at the $\mathrm{Fe}-\mathrm{ZrO}_{2}$ interface treated at $1673 \mathrm{~K}$.
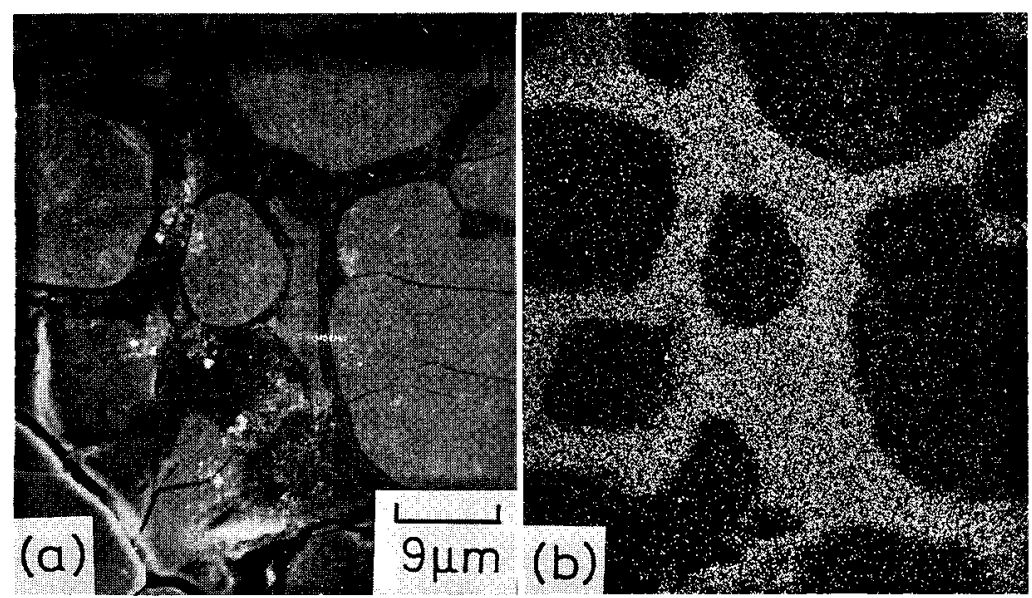

the interface. One of the authors ${ }^{8}$ ) has reported that $\mathrm{Al}_{2} \mathrm{O}_{3}$ at the interface decomposes to aluminum and oxygen and work of adhesion increases at low oxygen potential in the liquid nickel-alumina wettability experiment. Utilizing this result, two of the authors ${ }^{21)}$ have reported that the joining of $\mathrm{Al}_{2} \mathrm{O}_{3}$ to solid nickel can be attained in reducing atmosphere. These reports indicate that taking notice of the oxygen state at the metal-ceramics interface must be more effective to the joining of ceramics to metals.

"Field-assisted bonding" $\operatorname{method}^{22-28)}$ is the one which utilizes the sodium ionic conductivity of glasses or $\beta$-alumina ceramics at elevated temperatures and joins these materials to metals. On the other hand, the joining method proposed here is the one which utilizes the oxygen ionic conductivity of zirconia. Oxygen ions can be moved in the zirconia and the oxygen potential at the metal-ceramics interface can be controlled by applying a DG voltage to the interface. Interfacial reactions, they are, an oxidation of metal or deoxidation of $\mathrm{ZrO}_{2}$ can be accelated by applying a DC voltage. The wettability of zirconia can be improved and the joining of sprayed zirconia to metal substrates can be strengthened by the interfacial reactions.

\section{Conclusions}

The improvement of the joining strength between iron and sprayed zirconia was attempted by applying a DC voltage to the iron-zirconia interlace with an external DC power supply utilizing an oxygen ionic conductivity of zirconia after spraying zirconia onto the iron substrate. The main results obtained in this work are as follows:

(1) Oxygen potential at the interface can be controlled by applying a DC voltage to the interface using an external DC power supply.

(2) Application of a DC voltage to the interface improves the wettability of zirconia by liquid iron.

(3) When a DG voltage was applied to supply oxygen ions to the interface, iron in the form of liquid $\mathrm{FeO}$ penetrated into the grain boundary of zirconia at temperatures higher than melting point of $\mathrm{FeO}$. This is a mechanism for strengthening of the joining.

(4) The optimum depth of the penetration of iron was about a diameter of zirconia particle distance.

(5) When a DG voltage was applied to remove oxygen ions from the interfacc, zirconia was deoxidized to metallic zirconium at the interface and the metallic zirconium reacted with iron. The reaction improved the joining strength between iron and zirconia.

(6) The joining of sprayed zirconia to iron substrate can be strengthened after spraying zirconia.

(7) This is the new method to strengthen the joining strength after spraying zirconia.

\section{Acknowledgments}

The authors are most grateful to Mr. S. Tame, Undergraduate student, Osaka University, for his devoted experimental work and also to a financial support from Iketani Science and Technology Foundation.

\section{REFERENCES}

1) H. Takeda: SOKEIZAI, 27 (1986), 7.

2) G. Johner and K. K. Schweitzer: Thin Solid Films., 119 (1984), 301.

3) J. W. Watson and S. R. Levine: Thin Solid Films., 119 (1984), 185.

4) H. Kuribayashi, K. Suganuma, Y. Miyamoto and M. Koizumi: Am. Ceram. Soc. Bull., 65 (1986), 1306.

5) K. Nogi, H. Takeda and K. Ogino: Mater. Trans., JIM, 31 (1990), 83.

6) K. Nogi, H. Takeda, M. Sakashita and K. Ogino: Tetsuto-Hagané, 75 (1989), 259.

7) S. Kitahara: J.Jpn. Soc. Compos. Mater., 13 (1987), 37.

8) K. Ogino and H. 'Taimatsu: J. Jpn. Inst. Met., 43 (1979), 871.

9) H. Taimatsu, K. Ogino and F. Nakatani: J. Jpn. Inst. Met., 50 (1986), 176.

10) K. Ogino, H. Taimatsu and F. Nakatani: J. Jpn. Inst. Met., 46 (1982), 957.

11) B. E. Knox and E. H. Baker: J. Mater. Sci., 7 (1972), 476.

12) F. A. Halden and W. D. Kingery: J. Phys. Chem., 59 (1955), 557.

13) T. E. O'Brien and A.C.D. Chaklader: J. Am. Ceram. Soc., 57 (1974), 329.

14) K. Nogi, K. Ogino and T. Kurachi: Tetsu-to-Hagané, 74 (1988), 648

15) K. Ogino, K. Nogi and Y. Koshida: Tetsu-to-Hagané, 59 (1973), 1380.

16) K. Nogi, H. Takeda and K. Ogino: J. Jpn. Inst. Met., 53 
(1989), 927.

17) Yu. V. Naidich, V. N. Eremenko, V. V. Fesenko, M. I. Vasiliu and L. F. Klichenko: The Role of Surface Phenomena in Metallurgy, ed. by V. N. Eremenko, Consultant Bureau, New York, (1963).

18) C. Wagner: Z. Phys. Chem., B21 (1933), 25; 46 (1982), 480.

19) M. Hansen and K. Anderko: Constitution of Binary Alloys, McGraw-Hill Publ., New York, (1958), 741.

20) K. Sakata, K. Homma, K. Ogawa, O. Watanabe and K. Nii: J.Jpn. Inst. Met., 49 (1985), 540.

21) K. Nogi, H. Nakanishi, T. Sakamaki and K. Ogino:
Tetsu-to-Hagané, 75 (1989), 1126.

22) G. Wallis and D. I. Pomerantz: J. Appl. Phys., 40 (1969), 3946.

23) M. P. Borom: J. Am. Ceram. Soc., 56 (1973), 254.

24) P. B. Denee: J. Appl. Phys., 40 (1969), 5396.

25) G. Wallis, J. Dorsey and J. Beckett: Am. Ceram. Soc. Bull., 50 (1971), 958.

26) G. Wallis: J. Am. Ceram. Soc., 53 (1970), 563.

27) B. Dunn: J. Am. Ceram. Soc., 62 (1979), 545.

28) Y. Arata, A. Ohmori, S. Sano and I. Okamoto: Trans. JWRI, 13 (1984), 35. 